\title{
Mesurments of Sugars in Leaves on APPLE TREES
}

\author{
KELC, D., LAKOTA, M. \& Vindis, P.
}

Abstract: Synthesis of some important sugars (sorbitol, sucrose, glucose and fructose) in leaves were followed, in summer and autumn on 12-year old 'Golden Delicious' apple trees (Malus domestica Borkh.) grown in the experimental orchard. The treatments encompassed fruiting and non-fruiting (picked) trees. Each treatment involved four trees. Trees from the picked treatment were defruited at $13^{\text {th }}$ of August. Leaves for sugar analysis were sampled five times. For sugar analysis we used high pressure liquid chromatography (HPLC). Concentrations were calculated using the external standard, comparing standard and sample surfaces. Sugars in leaves were slightly, but not significantly increased in non-fruiting trees. Only at the end of the season we have a higher content of sugars in the leaves of fruiting trees. Fruits represented a power sink, so the absence caused changes in sugar levels in leaves. There were only minor differences observed when sugars were compared for fruiting and non-fruiting trees.

Keywords: sugars; leaves; mesurements; HPLC

II

II

II
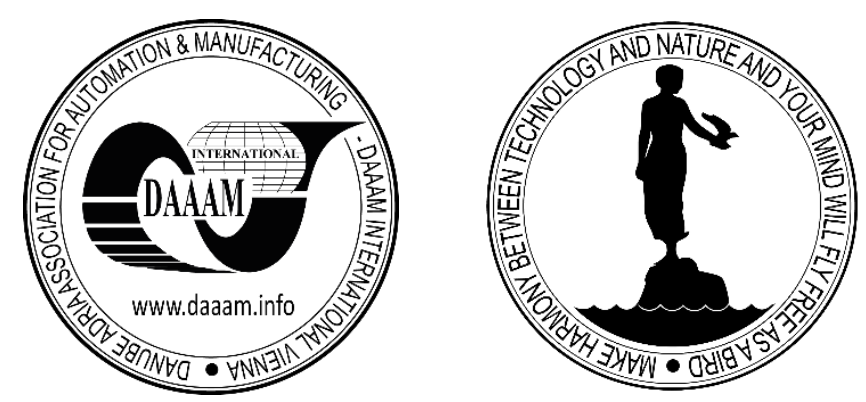

II

Authors' data: Msc. Kelc, D[amijan]; Assist. Dr. Vindis, P[eter]; Assoc. Prof. Lakota, M[iran]; University of Maribor, Faculty of Agriculture and Life Sciences, Pivola 10, SI-2311, Hoce, Slovenia, damijan.kelc@um.si, peter.vindis@um.si, miran.lakota@um.si

This Publication has to be referred as: Kelc, D[amijan]; Lakota, M[iran] \& Vindis, P[eter] (2016). Mesurments of Sugars in Leaves on Apple Trees, Chapter 19 in DAAAM International Scientific Book 2016, pp.207-216, B. Katalinic (Ed.), Published by DAAAM International, ISBN 978-3-902734-09-9, ISSN 1726-9687, Vienna, Austria

DOI: $10.2507 /$ daaam.scibook.2016.19 
Kelc, D.; Lakota, M. \& Vindis, P.: Mesurments of Sugars in Leaves on Apple Trees

\section{Introduction}

We want to determine seasonal changes in the amount of sorbitol, sucrose, glucose and fructose in leaves. The aim of this study is to check the hypothesis that the presence or absence of fruits effect the levels of certain sugars in the leaves of apple trees.

A large portion of the organic compounds of the fruits, with $80 \%$ of the apricot, 60 to $70 \%$ for apples, and 50 to $60 \%$ for plums and cherries, are in the form of dry matter, representing carbohydrates. Max. 5\% of solar radiation is converted to a carbohydrates in the process of photosynthesis. The optimal temperature for the photosynthesis of apple trees is between 20 and $30{ }^{\circ} \mathrm{C}$. (Friedrich and Fischer, 2000). In all apple trees more than $50 \%$ of the total carbohydrate represents sorbitol, although this value varies between the different parts of the tree (Wang et al., 1995). Glucose, fructose, sucrose and sorbitol represent the largest proportion of all sugars, and are largely dependent of the stage of fruit ripeness. Other sugars, maltose, arabinose, raffinose and xylose, most often occur as a result of the disintegration of other material, and also convert rapidly (Friedrich and Fischer, 2000).

Wibbe and Blanke (1995) in a study on the apple trees reported that the removal of fruits in August, affect the amount of starch and sucrose, in September and October, the concentration 2 to 3 times increase in the leaves. The concentration of glucose and fructose in this experiment was reduced. The amount of sorbitol can also be reduced by 6.6 to $5.7 \%$ of dry matter in the leaves in September and October, the volume rises to $9.5 \%$, after removing the fruits in Avgust. In bark and the roots of apple trees the quantity of starch reaches its peak in October, along with other soluble sugars: sucrose, glucose, fructose and sorbitol (Yoshioka et al., 1988). Movement of carbohydrates from the leaves to the fruits is not necessarily linked with the intensity of photosynthesis, the main role is played by the volume of reserves in the stock organs (Wibbe and Blanke, 1995).

Specific leaf weight should be less in the trees with fruits (Hansen and Ryungo, 1979). In the early period of development of the fruits, before the stage of fruit ripening, it was not observed any differences in chlorophyll and sugar content in the leaves of peach trees with fruits, and without them (Nii, 1997). Just one day after the removal of fruits, increases the amount of starch and sorbitol in leaves. When the fruits as a major sink are removed, the movement of sorbitol from the leaves is blocked. As a result, sorbitol is stored in mesophyll in leaves. Sorbitol does not reduce the intensity of photosynthesis in peach.

\section{Sorbitol, glucose, fructose and sucrose}

Sorbitol is the end product of photosynthesis in most temperate fruit crops. Sorbitol represents approximately $65-80 \%$ of the total soluble carbohydrates in the floem of apple trees. In most other cultured species are the main product of photosynthesis, sucrose and starch. Sorbitol as the final product of assimilation is moved from the leaves to the spending parts of the plants. (Faust, 1989). Industry 
produced sorbitol by the reduction of glucose. It is used as a sweetener for diabetics (Petauer, 1993).

Glucose is a monosaccharide, which is the most represented in fruits, vegetables and honey. In the nature is the glucose the most common sugar, directly is produced from the photosynthesis. The content of glucose and fructose in the ripe fruits of apple trees are different, in most cases, the fructose content does not exceed the levels of glucose (Petauer, 1993).

Fructose is fruit sugar. Together with glucose create disaccharide sucrose. The highest level of fructose in plants are in fruits and honey. The content of fructose in the fruits grow with the development of fruits. During the slow growth of fruits, fructose content is growing more slowly than in the periods of rapid growth of fruits (Wang et al., 1995). The authors concluded that the development of water stress increases the concentration of fructose.

Sucrose is a disaccharide, which can easily split in a process of hydrolysis to two monosaccharide, glucose and fructose. It is formed from glucose and fructose and located in the fruits and vegetable juices. The apple fruits have the largest proportion of sucrose among the other sugars. (Petauer, 1993)

\section{The determination of sugars by HPLC analysis}

High pressure liquid chromatography (HPLC) is a useful method and is more efficient than ordinary liquid chromatography. It is especially suitable for the analysis of foods. The most interesting are also the analysis of acids, sugars, vitamins and fat. It is a technique in analytical chemistry used to separate, identify, and quantify each component in a mixture. Each component in the sample interacts slightly differently with the adsorbent material, causing different flow rates for the different components and leading to the separation of the components as they flow out the column. To successfully chromatographic separation is necessary to make a compromise between resolution of the individual peaks, the speed of separation and the capacity of the column (Doyon et al., 1991).

Analysis of carbohydrates (glucose, sucrose, fructose, sorbitol) with HPLC system TSP (Thermo Separation Products), was carried out by using the column AMINEX HPX-87C, using distilled water as the mobile phase, flow rate of $0.6 \mathrm{ml} /$ min and the injection volume $20 \mathrm{ml}$. The operating system was OS / 2 Warp IBM (1994). Heating chamber for the column was: Mistral, Spark Holland. We used the pump type: P2000, and deaerator: X-ACTTM DEGASER. We used an automatic feeder patterns with thermostat AS 1000. The separation was carried out at a temperature of $850 \mathrm{C}$. The analysis was conducted $60 \mathrm{~min}$. Detection of sugar held by the detector Shodex RI-71 values of individual sugars in apple cultivars were determined by comparing the retention times obtained from the sample and standards. The concentration of each sample was calculated using the external standard, by comparing the obtained sample surfaces and the surfaces of the standards (standards, glucose, sorbitol, sucrose, fructose) of known concentration. 
An HPLC (figure 1) system (left) from left to right: A pumping device generating a gradient of two different solvents-a steel-enforced column and a detector for measuring the absorbance. And schematic representation of an HPLC unit (right).

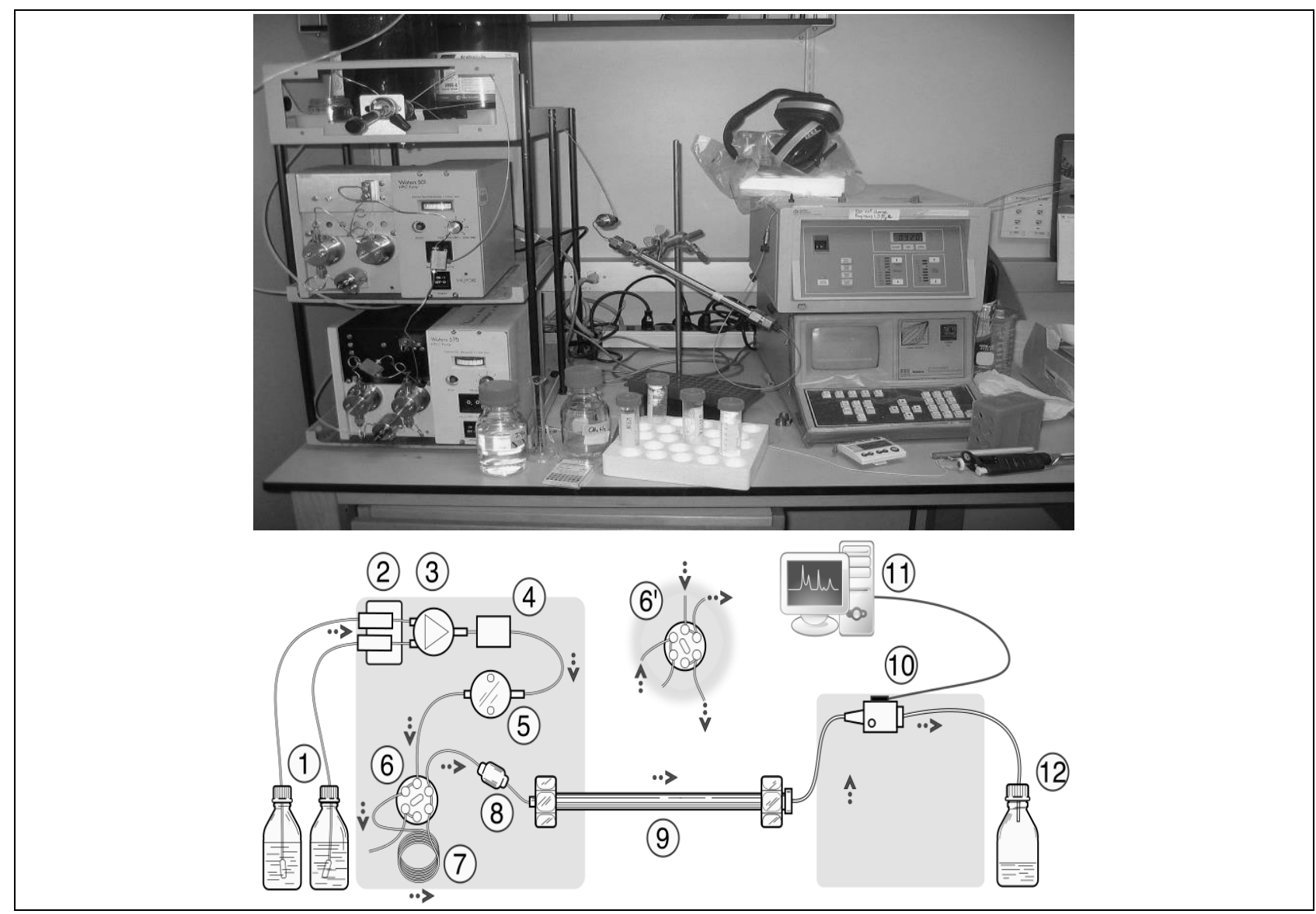

Fig. 1. An HPLC system (top) and HPLC unit (bottom) which consist of: (1) Solvent reservoirs, (2) Solvent degasser, (3) Gradient valve, (4) Mixing vessel for delivery of the mobile phase, (5) High-pressure pump, (6) Switching valve in "inject position", (6') Switching valve in "load position", (7) Sample injection loop, (8) Pre-column (guard column), (9) Analytical column, (10) Detector (i.e. IR, UV), (11) Data acquisition, (12) Waste or fraction collector (Wikipedia, 2016)

\section{Material and method}

\subsection{Material}

Measurements were made on summer and autumn at 12 years old apple trees, cv. 'Golden Delicious' in the experimental field of the Biotechnical Faculty. Basis for vaccination was M9. Trees from the picked treatment were defruited at $13^{\text {th }}$ of August. Each treatment involved four trees.

\subsection{Method}

Leaves for analysis of sugars was sampled five times. For each sampling we were taken ten leaves per tree. The first sampling was conducted on $2^{\text {th }}$ August, 11 days before removing the fruits. The following sample was carried out 8, 17, 38 and 50 days after removal of the fruits. Leaves were sampled always from annual, mature and well 
developed appropriate shoots, always at 10.00 a.m. in the morning. For sampling, we used only the leaf surface. The leaves were immediately after sampling frozen in liquid nitrogen.

Measurement data were statistically analysed by analysis of variance (ANOVA) using the program Statgraphics Plus 4.0. Differences between treatments were tested using the tests of multiple comparisons, such as LSD, and Duncan's test at the risk of $\alpha<0.05$.

\section{Results with discussion}

\subsection{Sugars in leaves}

Figure 2 shows glucose in leaves. The measurements shown averages with standard deviation. We can see that conduct in 'empty' and 'full' trees is fairly equal. In the third sampling in the leaves of 'empty' trees is observed the drastic reduction in glucose, which towards the end still grows. The difference would be possible because of the variability of results.

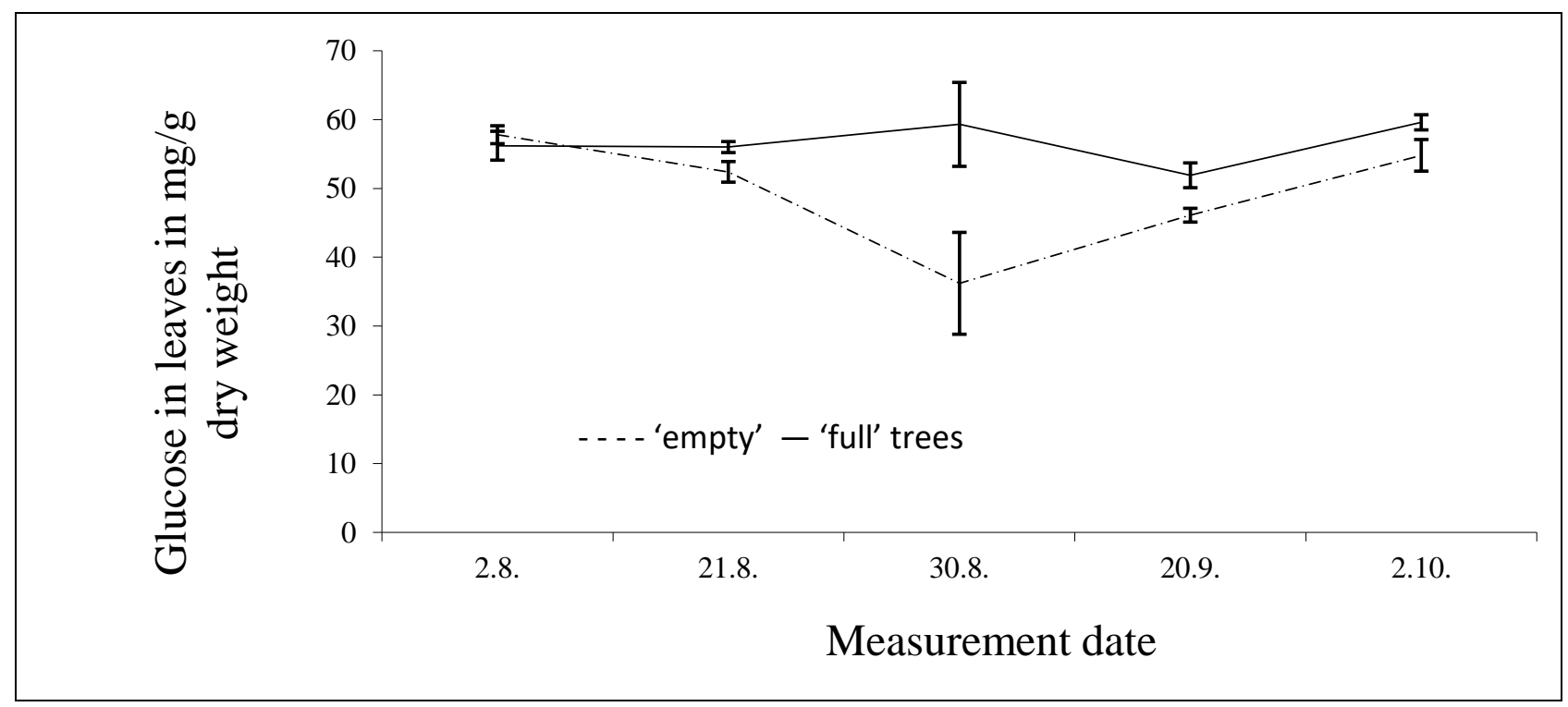

Fig. 2. Glucose in leaves in mg/g dry weight in 'Golden Delicious' for trees with and without fruits

Figure 3 shows fructose in leaves. The measurements shown averages with standard deviation. Higher fructose value have leaves of 'empty' trees, although the differences are very small and quite uniform. There is no statistically significant results. 


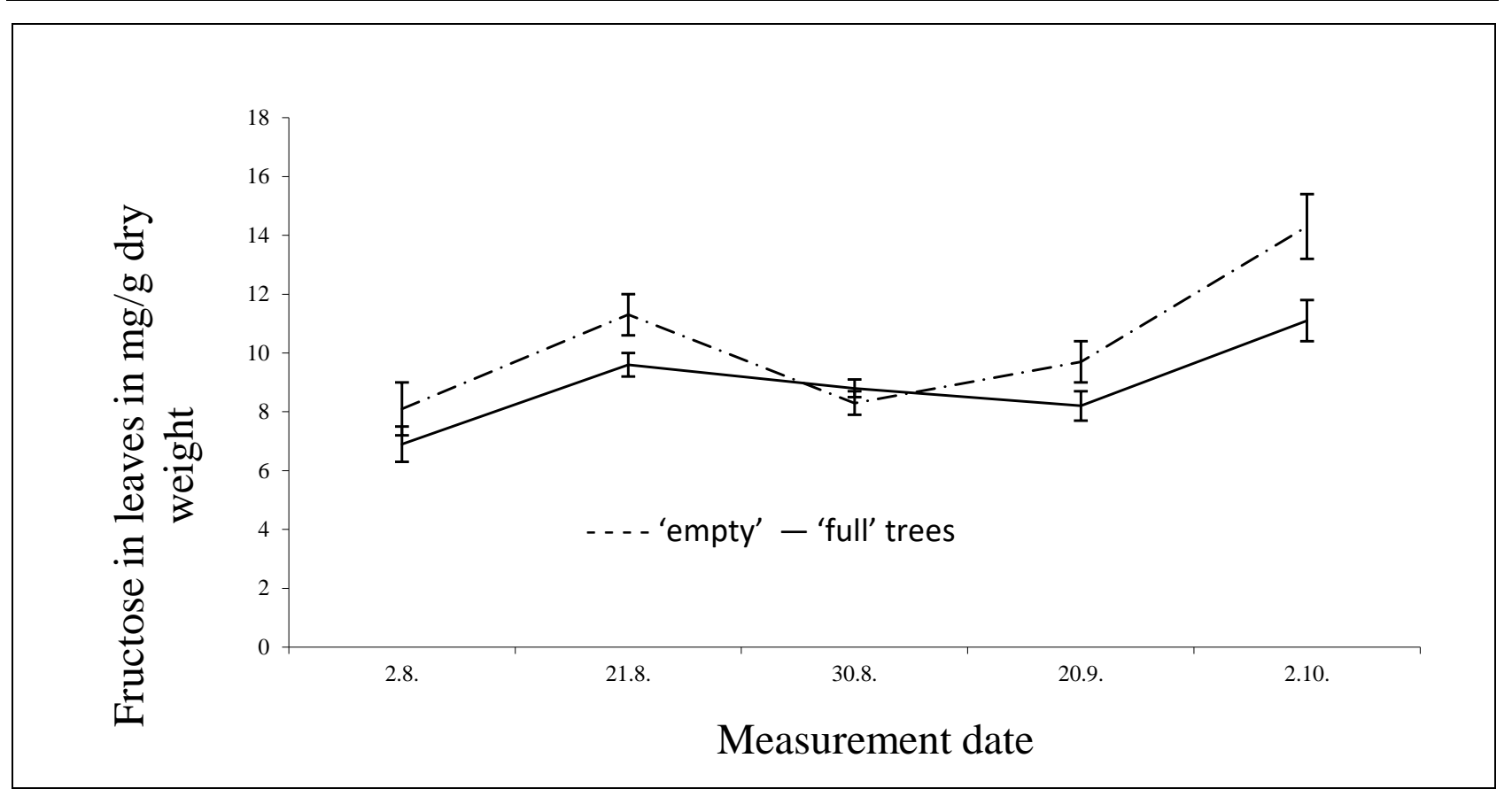

Fig. 3. Fructose in leaves in mg/g dry weight in 'Golden Delicious' for trees with and without fruits

Figure 4 shows sucrose in leaves. The measurements shown averages with standard deviation. The glucose content have no statistically significant differences between 'full' and 'empty' trees. Sucrose is another carbohydrate that is moved from the leaves of apple trees into the fruits (Hansen, 1970). In the leaves of 'empty' trees, the sucrose content does not change much from August to October. Oscillations is concentration of sucrose in the leaves is more evident in 'full' trees. This can be explained by the metabolic response of the leaves to the requirements of the sink synthesized sugars. In our study it is clearly shown an increase in sucrose content in times of growth and fruit development. To make easier the transportation of sucrose, which is transferred from the leaves to the fruits in pararhyme cells of the fruit, the sucrose is easily degraded to glucose and fructose (Yamaki, 1995).

Wibbe and Blanke (1995) in a study on the apple trees reported that the removal of fruits in August, affect the amount of starch and sucrose, in September and October, the concentration of which 2 to 3 times increase in data sheets. The concentration of glucose and fructose in this experiment reduced. The amount of sorbitol also reduced by 6.6 to $5.7 \%$ of dry matter in the leaves in September, in October, the volume rises to $9.5 \%$. 


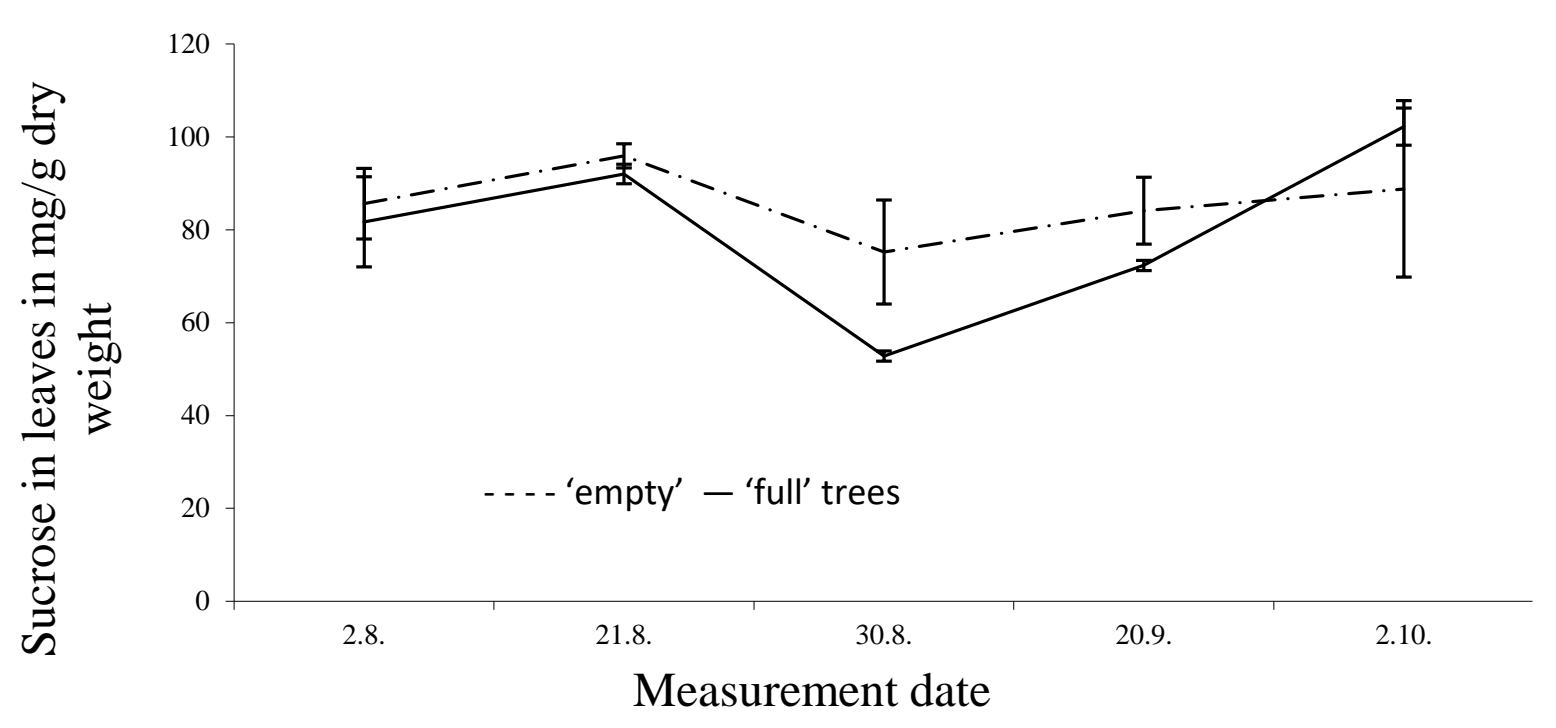

Fig. 4. Sucrose in leaves in $\mathrm{mg} / \mathrm{g}$ dry weight in 'Golden Delicious' for trees with and without fruits

Figure 5 shows sorbitol in leaves with standard deviation. Sorbitol content in all five measurements are extremely uniform, and there are no statistically significant differences between the treatments. Towards the end of sampling the levels of sorbitol significantly reduces. In apple trees is sorbitol the most often involved in the transporting though the plant (Loescher et al., 1987). We can conclude that sorbitol accumulates in the leaves of 'empty' trees, due to lower sink activities (Nii, 1997). In our last sampling the concentration of sorbitol in 'full' trees is almost the same as in 'empty' trees. As reported by Nii (1997), higher sorbitol content in leaves increased photosynthesis in peach trees. In our study, the minimum content of sorbitol at the end of the season is associated with lower activity of photosynthesis.

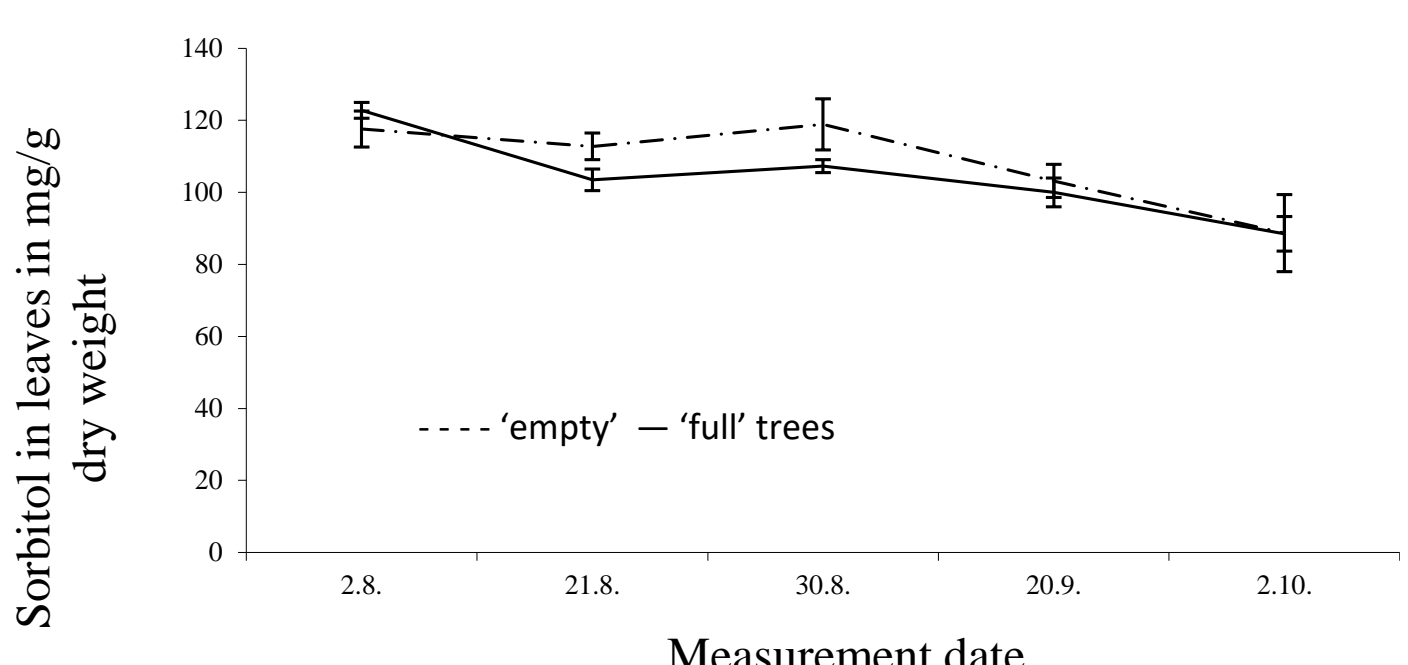

Fig. 5. Sorbitol in leaves in $\mathrm{mg} / \mathrm{g}$ dry weight in 'Golden Delicious' for trees with and without fruits 


\subsection{Total sugars in leaves}

Figure 6 shows total sugars in leaves. The measurements shown averages with standard deviation. It can be traced only slightly higher values of sugars in 'empty' trees, with no statistically significantly differences in comparison with the 'full' trees. On the other hand, stands out the last measurement when it appears the biggest difference in sugar content between 'full' and 'empty' trees. With the fruit ripening, the fruit sink strength decreases. It is observed a clear reduction of total sugars in the leaves till the last measurement. In the cultivar 'Golden Delicious' was a clear decrease in photosynthetic activity observed for the period from the end of September to October (Veberic et al., 2002).

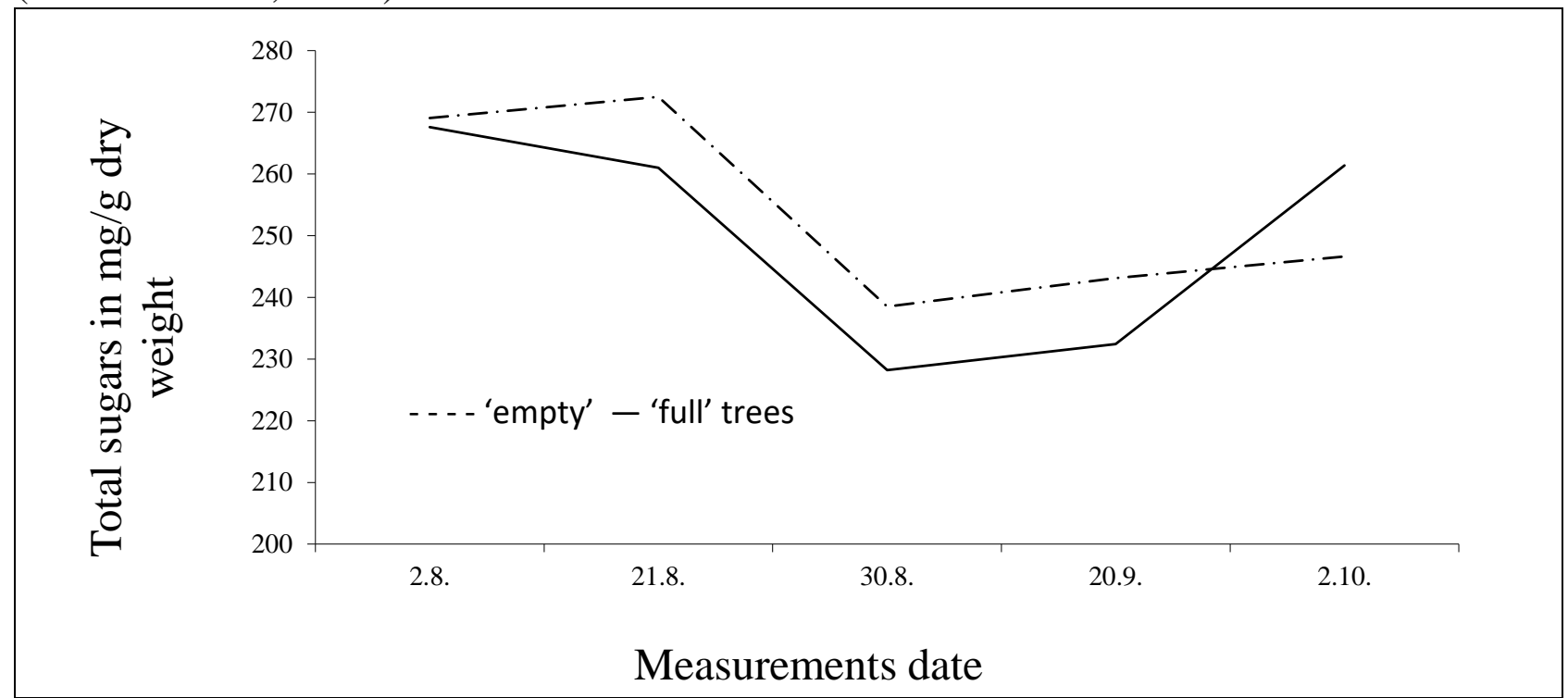

Fig. 6. Total sugars in leaves in $\mathrm{mg} / \mathrm{g}$ dry weight in 'Golden Delicious' for trees with and without fruits

In our case, we also observed a higher content of certain sugars in the leaves of 'empty' trees at a time when it was reduced photosynthesis (Kelc et al., 2015). It is interesting that this picture is reversed at the end of the season, when we have a higher content of sugars in the leaves of 'full' trees, compared to the 'empty' trees, which also means lower net photosynthesis in trees with fruits. Comparing the levels of total sugars and photosynthesis in the leaves, we find an interesting link. As we have seen, the net photosynthesis until the last measurement is higher in the 'full' trees (Kelc et al., 2015). Last measurements of photosynthesis indicates a higher value in the leaves of 'empty' trees. In total sugars, the situation is just the opposite. All the time we have a higher content of total sugars in the leaves of 'empty' trees. At the last measurement markedly increased content of total sugars in the 'full' trees. In a very short period of time reduces the power sink, represented by fruits. In the absence of strong stimulation by the sink, it is also lower the intensity of the photosynthesis, it decreased rapidly, so that the difference with the 'empty' trees is very visible.

To summarize, we can say that the early removal of fruits significantly reduced the level of photosynthesis and transpiration (Kelc et al., 2015), on the other hand, it has only a minimal impact on the carbohydrates in the leaves. The quantities of sucrose, sorbitol, fructose and glucose in the leaves shows a similar seasonal changes and 
developments as reported at the preliminary studies of Berüter $(1985,1997)$, which also have not reported of statistically significant differences between the treatments.

\section{Conclusions}

We studied synthesis of some important sugars (sorbitol, sucrose, glucose and fructose) in leaves, in summer and autumn on 12-year old 'Golden Delicious' apple trees (Malus domestica Borkh.). The treatments encompassed fruiting and non-fruiting (picked) trees. Sugars in leaves were not significantly increased in non-fruiting trees. We observed a higher content of certain sugars in the leaves of 'empty' trees at a time when it was reduced photosynthesis (Kelc et al., 2015). It is interesting that this picture is reversed at the end of the season, when we have a higher content of sugars in the leaves of 'full' trees, compared to the 'empty' trees, which also means lower net photosynthesis in trees with fruits. Our research efforts and future views are currently focusing on analysing of some sugars in bark and fruits in apple trees. Therefore we would get a complete view of the synthesis and accumulation of some important organic compounds in an apple tree. Certain technological acts could have a positive impact on the accumulation of assimilated carbohydrates in fruits and therefore their quality and easier and faster technological processes in the further processing and storage of fruits, like fruit sorting, applications techniques for plant protection (Rakun at al., 2015; Berk et al., 2016). This will provide a basis for production simulation model, which should be made for apple production in next observations similar as Vindis et al. (2010) made for biogas production.

\section{References}

Berk, P.; Hočevar, M.; Stajnko, D. \& Belšak A. (2016). Development of alternative plant protection product application techniques in orchards, based on measurement sensing systems: A review, Computers and electronics in agriculture, vol. 124: 273288

Doyon, G.; Gaudreau, M.; Gelais, D.; Beaulieu, Y. \& Randall C.J. (1991). Simultaneous HPLC determinantion of organic acids, sugars and alcohols. ISBN 148229784 - 9781482297843, Journal of Canadian Institute of Science and Tehnology, 24: 613-617

Friedrich, G. \& Fischer, M. (2000). Physiologische grundlagen des obstbaues. 3. Ausgabe. ISBN 3-8001-3475-6, Stuttgart, Eugen Ulmer Verlag: 512

Hansen P. (1970). 14C-studies on apple trees. V. Translocation labelled compounds from leaves to fruit and their conversion within the fruit. Physiol. Plant, 23: 564-573

Hansen P. \& Ryugo K. (1979). Translocation and Metabolism of Carbohydrate Fraction of 14C-photosynthates in 'French' Prune, Prunus domestica L. ISBN 0521236983 - 9780521236980, J. Amer. Soc. Hort. Sci., 104, 5: 622-625

Kelc, D.; Vindis, P. \& Lakota, M. (2015). Mesurments of Photosynthesis and Transpiration on Apple Trees. V: Katalinić, Branko (ur.). DAAAM International 
Kelc, D.; Lakota, M. \& Vindis, P.: Mesurments of Sugars in Leaves on Apple Trees

scientific book 2015, (DAAAM International scientific book, ISSN 1726-9687). Vienna: DAAAM International Publishing, 2015, 199-208

Loescher W.H. (1987). Physiology and metabolism of sugar alcohols in higher plants. Physiol. Plantarum, 70: 533-557

Nii N. (1997). Changes of Starch and Sorbitol in Leaves Before and After Removal of Fruits from Peach Trees. ISSN 0305-7364, Annals of Botany, 79: 139-144

Petauer T. (1993). Leksikon rastlinskih bogastev (Lexicon of plant resources). Ljubljana, Tehniška založba Slovenije: 699

Rakun J.; Berk P. \& Lakota M. (2015). Fruit sorting based on texture analysis and support vector machine classification. V: Katalinić, Branko (ur.). DAAAM International scientific book 2015, (DAAAM International scientific book, ISSN 17269687). Vienna: DAAAM International Vienna, 2015, 209-218

Vindis, P.; Stajnko, D.; Berk, P. \& Lakota, M. (2010). Qualitative multi-criteria evaluation of energy crops. V: Katalinić, Branko (ur.). DAAAM International scientific book 2010, (DAAAM International scientific book, ISSN 1726-9687). Vienna: DAAAM International Publishing, 2010, 99-116

Wang Z.; Quebedeaux B.; Stutte G.W. (1995). Osmotic adjustment: Effect of water stress on carbohydrates in leaves, stems and and roots of apple. ISBN $4431552510-$ 9784431552512, Australian Journal of Plant Physiology, 23, 3: 345-251

Wibbe, M.L. \& Blanke, M.M. (1995). Effects of defruting on source-sink relationship, carbon budget, leaf carbohydrate content and water use efficiency of apple trees. ISSN 0137-5881, Physiologia Plantarum, 94: 529-533

*** https://en.wikipedia.org/wiki/High-performance_liquid_chromatography_- The Free Encyclopedia, Wikipedia (2016), Accesed on:2016-09-10

Yamaki S. (1995). Physiology and metabolism of fruit development-Biochemistry of sugar metabolism and compartmentation in fruits. Acta Hort., 398: 109-120

Yoshioka H., Nagai K., Aoba K., Fukomoto M. (1988). Seasonal changes of carbohydrates metabolism in apple trees. ISSS 3-4, Scientia Horticulturae, 36: 219227 